\title{
Exchange Rate Forecasting and Value-at-Risk Estimation on Indonesian Currency Using Copula Method
}

\section{Kevin Bastian Sirait ${ }^{1}$ and Batara Maju Simatupang ${ }^{2}$}

\author{
${ }^{1}$ Parahyangan Catholic University, Indonesia, e-mail: a2017811012@student.unpar.ac.id \\ ${ }^{2}$ STIE Indonesian Banking School, Indonesia, e-mail: bbatara.ms@ibs.ac.id
}

\begin{abstract}
This study aims to determine the future value and the value-at-risk estimation of four selected currencies, namely United States Dollar (USD), Australian Dollar (AUD), European Union Euro (EUR) and Japanese Yen (JPY) against Indonesian Rupiah (IDR). The Monte-Carlo simulation is implemented to estimate the future value of each currency relationship and integrating it with the concept from the copula method; the risk value estimation is conducted using Value-at-Risk (VaR), and the VaR estimation is within the range of $90 \%, 95 \%$ and $99 \%$ confidence interval. The copula method we use in this study is Clayton copula because it has the highest log-likelihood value compared to Frank and Gumbel copula; with an addition, each currency uses their regressive model to see if the selected exchange rates have the characteristic of a seasonal or non-seasonal pattern. The result we obtain in this study are JPY/IDR, and EUR/IDR relationships have the highest simulated loss and estimated risk values in each confidence interval.
\end{abstract}

Keywords: Value-at-Risk, Monte-Carlo Simulation, Copula Methods, Exchange Rates

\section{Introduction}

President Jokowi in his remark at the IMF-World Bank Annual Meetings Plenary Sessions at the Bali Nusa Dua Convention on October $12^{\text {th }} 2018$ stated: "Monetary and fiscal policies are needed to support the impact of the trade war, technological disruption and uncertainty in the market". The statement serves as advice to the world to turn their attention in improving global financial conditions so as not to collapse as it had ever happened.

History records, in 1997/1998 there was an Asian crisis which brought Indonesia to the brink of crisis and prolonged recession. The Asian crisis that happened in 1997/1998 was so devastating, however, is not purely due to currency crisis but with an addition of financial and banking crisis (Krugman, et al., 2018, p. 748). Banks poor performance on the Asian crisis contributed to the disruptions on the nation's economy by reducing the channels of credit to the company. The reduction of credit channels increases the difficulty for the companies to survive in times of crisis.

The banking crisis in Asian countries is closely related to appreciations followed by sharp depreciation in real effective exchange rates and parallel movements in the gross external liabilities of the banking sector (Hardy \& Pazarbaşioğlu, 1998). Kaminsky \& Reinhart (1999) found that the peak of banking crises occurred most often after the currencies fell, in which amplified the effect of the banking crises. When the currency and banking crises occurred together (twin crises), the finding shows that the economic fundamentals tend to be worse, the states of the economy become weaker, and the effect of the twin crises are getting worse (Kaminsky \& Reinhart, 1999). Simatupang (2007) stated that the overall cost of resolving a banking crisis on the Indonesian economy had reached 659.59 trillion IDR or $51.03 \%$ of gross domestic product (GDP) realised in 2000 .

During the global financial crisis of 2008, the issue of foreign exchange rate risk was a scourge that has always been a burden due to the weakening of the exchange rate over the strength of the world's anchor currency. In order to manage and mitigate the risk regarding the impact of the regional currencies, forecasting capabilities are needed by applying an analytical tool the level of dependence between exchange rates relationship. According to Coval et al. (2009), the dependency between random variables is crucial for risk management and pricing. The movement between exchange rates can affect the rate of the future cash flow of a company and even at the scale of a country. For 
example, if the local currency becomes stronger over time it can bring benefits to the owner of the currency; however, if it weakens over time, it can reduce the profitability of the currency holder.

Several studies on forecasting and variable dependence in multivariate distribution; see Diks et al. (2010), Nguyen \& Molinari (2011) and Righi \& Ceretta (2011). The modelling in multivariate variables allows measurement of risk in market risk, especially in exchange rate risk. In general terms, multivariate analysis can be used to understand the relationship between two variables or more to capture the dominance of the variables in those relationships while considering the influence and the effects of the variables.

In this research, we consider an empirical application to the daily exchange rates returns of Australian Dollar (AUD), European Union Euro (EUR), Japanese Yen (JPY) and United States Dollar (USD) against Indonesian Rupiah (IDR). The data we use in for this research are spanning from 2008: M1 to 2018: M9. We choose Monte-Carlo simulation to predict the future value of the selected currencies relationship based on the characteristic of currencies relationship from the implementation of the copula. Furthermore, the copula method is implemented to understand how each currency interacts with each other and learn which currencies relations has the highest potential losses.

Risk Management. The concept of risk assessment and risk management is rather young in the scientific field, not more than 40 years old (Aven, 2016). Even though risk management is considered young, the concept and the benefit of risk management had already given to the nations and enterprises is immense. There are many types of research regarding risk management, such as Hallikas et al. (2004), Chen \& Hong (2007), Michalski (2009), Platon \& Constantinescu (2014), Ito et al. (2015) and Quang et al. (2018). As these references show, the concept of risk management has evolved and has its benefits regarding the estimation of risk contained in the activities of the company. Aven (2016) stated that in financial, business and operational research, the concept of risk management and risk assessment are conducted to analyze the risk characteristics and to provide relevant information regarding the risk in the context of decision making. One of the techniques in measuring risk within the financial portfolio is Value-at-Risk (Var), which implemented a mathematical and probabilistic approach regarding risk estimation.

The needs of risk management were increased tremendously due to the need of the enterprises on anticipating an unexpected event that might cause severe impact, and an abrupt movement of the financial asset could bring the devastating result to unprepared institutions or companies due to the changes in the environment. Dionne (2013) explains the origin of risk management and how the concept applied to mitigate the risk faced by the institutions, especially in the financial sector. However, in this modern era, the subject of risk management is not only applied in the financial field but rather on all the fields of the working environment of a company and even the environment of a nation. Risk comes in many forms, and the sources of it can come from anywhere, but this does not mean it will not affect the profitability and the financial conditions of a company. On the contrary, the risk faced by the company may trigger other risk and caused a devastating impact.

Based on that brief explanation, risk management has three main steps on handling a risk, which are: identifying the source of the risk, measuring the impact of the risk and finally, controlling or mitigating the risk itself (Chen \& Hong, 2007; Dionne, 2013; Aven, 2016). From the steps on handling the risk, it gives an understanding that risk may come from anywhere, it has a different scale of impact, and each risk has its mitigation strategies. Each risk is different for every company, especially for a company operating in the financial sector. Some of the risks arising from the financial sector are credit risk, liquidity risk, solvency risk and exchange rate risk. These risks exist in every activity conducted by the companies and even nations.

For the sole purpose of this research, we only focused on the exchange rate risk to determine the future value of the selected currencies and its VaR estimation.

The Monte-Carlo simulation. The Monte-Carlo simulation revolves on the random variables from known distribution to simulate all the potential result based on the determined parameters and the data used for risk management; on the Monte-Carlo simulation, all the properties of the variables are 
designed with the properties of the financial portfolios (Jorion, 2009, p. 89). Some of the financial portfolios are stock prices, exchange rates, commodity prices and yield bonds. The method of MonteCarlo simulation is one of the most common and generally used on determining the potential risk in financial portfolios. One of the benefits of Monte-Carlo simulation in the financial sector is that it helps the decisions maker to take risks into considerations in a quantitative manner and producing the most suited decision on controlling or mitigating the risk based on the scenarios for each particular event. According to Staum (2002); Chen \& Hong (2007), there are three reasons why Monte-Carlo simulation is suitable for simulations, which are: (1) Monte-Carlo simulation is applicable in most situations, (2) it doesn't depend on the dimensionality of the problem at hand and finally, (3) it is suitable to problems with high dimensionality. Furthermore, the simulation on economic decisions can is applicable in all settings of problems including procedures, policies and operational rules to cope with pricing policies, decision control and decisions adaptation (Platon \& Constantinescu, 2014). There are many types of research regarding the implementation of Monte-Carlo simulation due to its capability on simulating all the potential events in the movement of exchange rates, such as Diks et al. (2010), Kawakami (2013), Cho \& Shin (2016) and Khalaf \& Saunders (2017).

According to Staum (2002), the concept and the implementation of Monte-Carlo simulation in the field of financial engineering to find the best combinations of profit and potential losses. In which, this approach has similar steps in simulating the potential event based on the data at hand within the specific time, measuring the financial derivatives from the simulations and represent the result in the form of distribution. The result of Monte-Carlo simulation can be efficient and correct due to the advancement of technology and efficient algorithm (Chen \& Hong, 2007). Regarding the research on improving and implementation of computational power on computational finance is conducted by Alexandrov et al. (2011), in which Alexandrov et al. (2011) implementing the parallel Monte-Carlo algorithms and its potential based on the scalability, speed and fault-tolerance perspectives in computational finance.

In order to implement the Monte-Carlo simulation, the following steps is given as follows: (1) design or choose stochastic process for the risk factor, (2) generate random variables to represent risk factor at the determined horizon, (3) calculate the values of the portfolios based on the determined horizon and finally, (5) calculate the result based on the specified iterations on the simulations. Even though Monte-Carlo simulation is applicable in most situations, it is worth to point out that a simulation is as good as it could be, based on the parameters, variables and conditions that of the simulation.

Value-at-Risk. Value-at-Risk (VaR) defined as an estimation of maximum losses that may affect the financial portfolio on certain times of period based on the determined confidence interval and, VaR can be seen as a cut-off point where financial losses will not happen within certain probability (Jorion, 2009 , p. 34). In other words, VaR is used to measure risk exposure in the financial sector such as commercial activities, investment and transaction based on the movement in the market over a specific time regarding their potential losses. The needs of measuring risk within the financial portfolio increased tremendously due to the potential of an abrupt movement that may happen in the market. One of the cases of sudden movement in the market is the Asian financial crisis of 1997/1998. The case of the Asian financial crisis of 1997/1998 had affected the unprepared parties in the market which results in a significant amount of financial losses.

Adamko et al. (2015) explain the origin, ideas and concept of $\mathrm{VaR}$, with an addition of its disadvantage and advantage. The concept of measuring risks and finding the potential losses within the financial portfolio had started since 1888, and it is attributed to Francis Edgeworth (Adamko, et al., 2015). Fortunately, there are many variations, and approaches on implementing VaR and the barriers of calculation using VaR has been decreased tremendously due to the advancement of technology, in which allows many researchers to optimize the VaR estimation to the financial portfolio by implementing the computational power.

Traditionally, VaR calculation and estimation within the financial portfolio can conduct in three ways: (1) Monte-Carlo simulation, (2) historical simulation and (3) parametric simulation (Adamko, 
et al., 2015). There are many types of research regarding the implementation of VaR to the financial portfolio, such as Neftci (2000), Cakir \& Uyar (2013), Ogawa et al. (2018) and Fink et al. (2018). The concept and the implementation of $\mathrm{VaR}$ have always been one of the most important and widely used tools for companies and even nations to measure the risks and its potential losses within the market risk, especially in the field of exchange rate movement.

Time Series Forecasting. Time series is defined as a sequence of observation taken continuously in time (Box, et al., 2016, p. 1). For each time series data, the nature of it is not always the same. In order to find the character and the nature of the data, time series modelling is necessary. The primary purpose of time series modelling is to find the data characteristics to develop the most suitable model, in which can be used to forecast the future value of a variable based on the nature of the data at hand. In simple terms, time series modelling can be used to predict the future value of a specific data by understanding the past. However, it is also worth to point out that the characteristic of the time series data used for the time series forecasting dictates which forecasting model are appropriate for it.

There are two types of model in time series forecasting based on the data characteristic, which is nonseasonal and seasonal forecasting. A time series is non-seasonal if the data used in the forecasting mechanism is stationary; otherwise, it is called a seasonal time series. These two types of models determined either Auto-Regressive Integrated Moving Average (ARIMA) or Seasonal AutoRegressive Moving Average (SARIMA) are most appropriate to be applied based on the nature of time series data. However, if the data found to be non-stationary; differentiation method can transform non-stationary data into stationary.

Some of the researches regarding ARIMA implementation in the economic theory and risk management; see Appiah \& Adetunde (2011) and Délèze \& Korkeamäki (2018). In the case of Appiah \& Adetunde (2011), the forecasting of the exchange rate between Ghana Cedi and USD shows that the relationship between the two currencies is non-stationary in nature; to solve the non-stationary problem, the differencing method is applied which resulting the most appropriate model for the Ghana Cedi and USD is ARIMA $(1,1,1)$. The same problem also occurred in the case of Délèze \& Korkeamäki (2018), in which the model of ARIMA $(1,1,1)$ is applied to predict the interest rate fluctuations in Europe.

However, it is possible for ARIMA to be unable to make the data stationary. This event may happen if the time series data used in the analysis is inherently non-stationary no matter how many times the differencing method used to the ARIMA model. To solve this problem, the SARIMA model can be applied to forecast the selected value if the is non-stationary. Some of the researches regarding the implementation of SARIMA; see Lidiema (2017) and Makatjane et al. (2018). In order to integrate the nature of the seasonal pattern within the data, seasonal differencing is applicable to handle seasonal data. In the case of Lidiema (2017), the model of SARIMA $(1,1,0)(0,0,1)$ is appropriate for forecasting the inflation rates in Kenya. In the case of Makatjane et al. (2018), the SARIMA model is implemented to study the impact of the 2008 financial crisis on regarding exchange rate in South Africa.

Copula Methods. The financial variables can be dependent. In order to find the dependencies between financial variables, it is possible to implement the copula method to associate the financial variables into a joint distribution (Jorion, 2009, p. 38). The main benefit of copula on assessing the relationship between variables is by modelling the marginal distribution and the structure of their respective dependence variables. There are some of the researches regarding the implementation of copula on exchange rates relationship; see Patton (2006), Diks et al. (2010) and Mahfoud \& Massmann (2012). According to Mahfoud \& Massmann (2012), the copula method was first introduced by Abe Sklar in 1959 and for the first study in implementing the copula method in the economic context was done by Embrechts et al. (1999).

There are three types of the copula, which are: (1) fundamental copula, (2) explicit copula (also known as Archimedean copula) and (3) implicit copula (Mahfoud \& Massmann, 2012). For each copula type, it has its characteristic in defining the dependence and independence level of each 
variable's relationship. In this context, the relationship can be in perfectly positive or negative. This research focuses on the Archimedean copula which is implemented to measure the dependence level for each exchange rates relationship, and it is used to produced correlation values to measure its VaR estimation.

Archimedean copula has three approaches to capture the dependence level of the relationship between variables, which are: Clayton copula, Frank copula and Gumbel copula (Mahfoud \& Massmann, 2012). The scope of each approach are: first, Clayton copula is used to study the correlation of the variables from their lower tail dependence. Second, Gumbel copula is used to study the dependence level of the variables from their upper tail dependence and finally, Frank copula is used to capture the dependence level between variables from either side of the tail. The copula approaches in Archimedean copula has Fréchet-Hoeffding bound. Fréchet-Hoeffding bound represents the dependence level of the variables in the copula and Fréchet-Hoeffding bound can be positive and negative dependence for the variables. However, the role of Fréchet-Hoeffding bound in each of the copula methods is different. Explain as follows: first, the Clayton copula cannot attain the FréchetHoeffding bound due to the restriction which resulting the Clayton copula cannot account the negative dependence. Second, the Gumbel copula is similar to the Clayton copula where the Gumbel copula represents the case of independence and positive dependence. Lastly, in the case of Frank copula, it can attain the upper and lower Fréchet-Hoeffding bound.

In simple terms, the concept of dependence in Fréchet-Hoeffding bound within the copula describes as follows: if the approximation is in Fréchet-Hoeffding upper bound, this means that the relationship between the variables has high correlation and realization. If the variables relationship is in the state of high correlation and realization; it is called comonotonicity or perfect positive dependence. Otherwise, it is called counter-monotonicity or absolute negative dependence.

\section{Research Methodology}

We collect daily data spanning from 2008: M1 to 2018: M9 on the exchange rates movement from the Bank Indonesia (2018) websites. The currencies we used in this research are Australian Dollar (AUD), United States Dollar (USD), European Union Euro (EUR) and Japanese Yen (JPY) against Indonesian Rupiah (IDR). In finding the future value of each currency the Monte-Carlo simulation is used, measuring the correlation of each variable is using copula method and producing the VaR estimation using the forecasted result from the exchange rates combines with the characteristic of the relationship of each variable. However, in order to determine the most suitable model for each of the currencies, we have conducted a regressive model test to capture each currencies characteristic and to determine if the currency moves in a seasonal or non-seasonal pattern. The descriptive statistics of each currency is in Table 1.

Table 1. Descriptive statistics of USD, AUD, EUR, JPY Against IDR.

\begin{tabular}{lrrrr}
\hline Descriptive Measures & 1 USD/IDR & 1 AUD/IDR & 1 EURO/IDR & 100 JPY/IDR \\
\hline Mean & 11230.16 & 9578.25 & 14186.95 & 11261.48 \\
Median & 11181 & 9875.96 & 14416.51 & 11333.66 \\
Standard Deviation & 1950.95 & 978.72 & 1580.91 & 1072.37 \\
Max & 15002 & 11462.14 & 17552.82 & 13528.08 \\
Min & 8502 & 6432.72 & 11089.74 & 8355.73 \\
Skewness & 0.1776 & -0.518 & -0.0539 & -0.5202 \\
Kurtosis & 1.4287 & 2.3474 & 1.9204 & 3.1285 \\
Number of observations & 2623 & 2623 & 2623 & 2623 \\
\hline
\end{tabular}


Based on the movement of each exchange rates, all the exchange rates we selected in this research had an abrupt movement in 2008 due to the 2008 financial crisis. This abrupt movement has the potential to cause the exchange rates to move in a non-stationary pattern. The method we use to test if the times series data is stationary or not is by implementing the Augmented Dickey-Fuller (ADF) test. If the p-value of the ADF test is equal to 1, then there is an indication of the time series data is non-stationary. However, if the p-value of the ADF test is below 0.05, then the time series data is stationary. To validate the result of the ADF test, we used c-value (critical value) from the ADF test and compared it with the result of the t-test. If the c-value is larger than t-test, it means that there is an indication of unit root within the data; otherwise, there is no indication of a unit root.

The next step before producing the future value of the exchange rates is to determine the most appropriate regressive model for each currency. The span of the differencing method for the ARIMA and SARIMA model are spanning from 0 to 2 . The span of the differencing method is also applied to auto-regressive (AR) and moving average (MA) for each currency. The model selection for each currency is determined from $p$-value, if the corresponding model is statistically significant then it becomes on the candidate to be tested in Akaike Information Criterion (AIC) to entirely determined the most appropriate model for the selected currencies. The lowest value of AIC is considered to be the most appropriate model.

After the stage of finding the most appropriate regressive model for each currency, then we compare each type of copula with the currencies. This step is necessary to capture the nature of the dependence level of the exchange rates relationships. The copula type to be tested with each currency relationships are Clayton copula, Frank copula and Gumbel copula. In simple terms, this test is conducted to capture the dependence position of each exchange rate relationship and to entirely determined if the exchange rates relationship has the characteristic of perfectly positive dependence or negative dependence according to the definition and the concept of Archimedean copula.

In order to produce the future value of each exchange rates, we use the Monte-Carlo simulation. However, in this research, we used the daily returns of each selected currencies. In the stage of forecasting the future value of each currency, each currency has used their most suitable regressive model. The horizon of the Monte-Carlo simulation in this research are 500 days forward, and the number of trials in the simulation is 2000 trials. The future value of the exchange rates is implemented to find the lower and upper bound of the future exchange rates movement.

The VaR estimation of the exchange rates relationship we used to be the daily returns of each currency. However, due to the nature and the definition of the Archimedean copula, the VaR estimation is based on the dependence and the correlation of the exchange rates relationship. The purpose of the $\mathrm{VaR}$ estimation in this research is to find the highest simulated loss in the exchange rates relationship that is within the range of $90 \%, 95 \%$ and $99 \%$ of the confidence interval. The horizon and the number of trials that are the same as the Monte-Carlo simulation and exchange rates forecasting. However, the only difference in this VaR estimation is that the horizon 100 days forward. The applications we used in this research are Matlab and Minitab to simulate the future value of the exchange rates and estimating the $\mathrm{VaR}$ for each respective exchange rates relationship.

\section{Result and Discussion}

Before we are conducting the VaR estimation and the forecast using the Monte-Carlo simulation, first we need to understand the nature of each exchange rates movement to see if the time series data is in the state of stationary or non-stationary. From Figure 1, all the currencies have similar fluctuations in the year of 2008. The cause of the fluctuations is due to the 2008 financial crisis. 

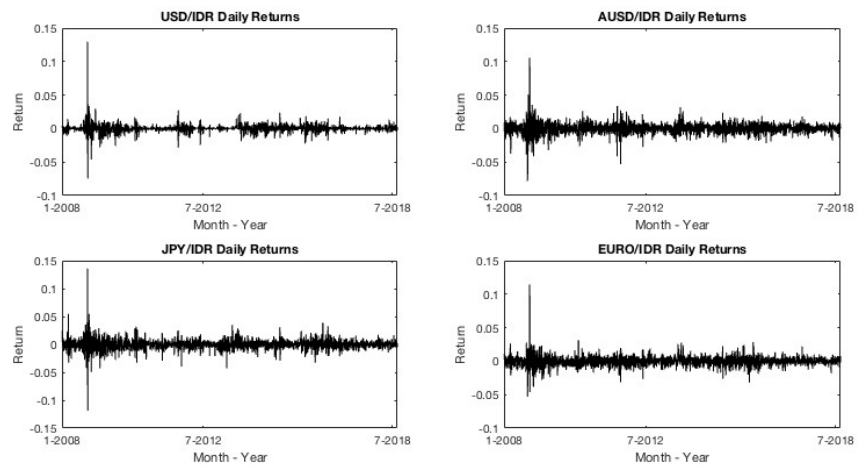

Figure 1. Daily returns USD, AUD, EUR, JPY against IDR.

However, Figure 1 is unable to capture the nature of the time series data and most of all it does not show if the data is either stationary or non-stationary. In order to find the characteristic of the time series data is stationary or not, the ADF test can find the time series data characteristics at hand.

Table 2. ADF test.

\begin{tabular}{ccccc}
\hline Currency & $\mathrm{p}$-value & $\mathrm{h}$ & $\mathrm{t}$-test & $\mathrm{c}$-value \\
\hline USD & 1 & 1 & -53.8024 & -1.9416 \\
AUD & 1 & 1 & -51.8764 & -1.9416 \\
EUR & 1 & 1 & -50.2679 & -1.9416 \\
JPY & 1 & 1 & -53.6166 & -1.9416 \\
\hline
\end{tabular}

Based on Table 2, the result regarding the ADF test shows that all the currency is not statistically significant due to the p-value of each respective currency is higher than 0.05 . In other words, all the currencies have an indication of unit root characteristic and all of the currencies is non-stationary. Because all of the currencies are in the state non-stationary, the differencing approach had to be implemented to remove the characteristic of non-stationary and random walk pattern from the time series data. Based on the result, all the currencies have higher c-value compared to the t-test, which has an indication of non-stationary pattern or unit root within the time series data.

Based on the ADF test, the result shows that the time series data we used in this research are nonstationary. However, the ADF test result does not explain if the currencies are correlating one and another. The correlation matrix analysis can find the correlation of each currency. The result and the plot of the correlation matrix analysis are in Figure 2.

From the correlation matrix in figure 2, the most substantial relationship between each exchange rates is between the relationship of USD/IDR and JPY/IDR with the value of 0.70 while the weakest correlation level belongs to JPY/IDR and AUD/IDR with the value of 0.14 . 


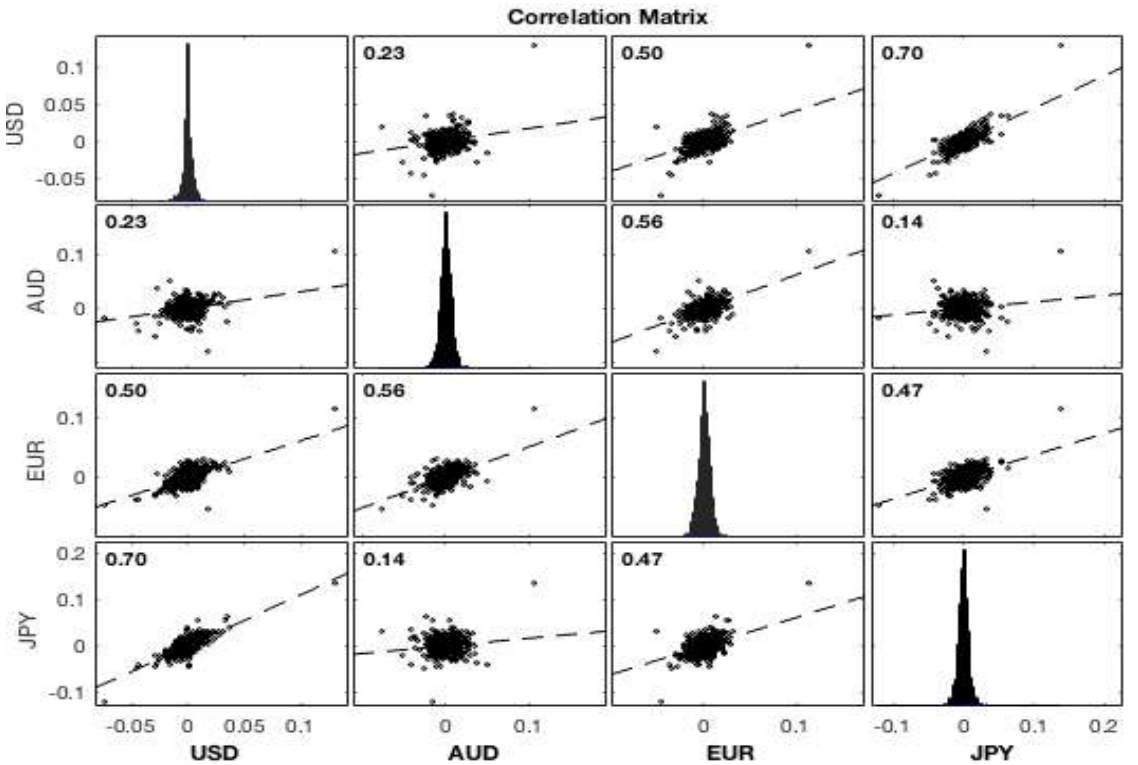

Figure 2. Correlation matrix USD, AUD, EUR and JPY.

The characteristic of the time series data in each currency is non-stationary. Time series analysis is implemented to find the most appropriate ARIMA or SARIMA model for each currency. The differencing approaches span from 0 to 2 . The differencing span is applied to ARIMA and SARIMA model and tested using the AIC test. The result of the AIC test is in Table 3.

Table 3. AIC test.

\begin{tabular}{|c|c|c|c|c|}
\hline \multirow{2}{*}{ Model } & \multicolumn{4}{|c|}{ Currency } \\
\hline & USD & AUD & EURO & JPY \\
\hline ARIMA $(1,1,0)$ & & & & -1.5892 \\
\hline ARIMA $(0,1,1)$ & & & & -1.6948 \\
\hline ARIMA $(1,1,1)$ & & & & -1.6957 \\
\hline $\operatorname{ARIMA}(2,1,1)$ & -1.9351 & & & -1.6966 \\
\hline $\operatorname{ARIMA}(1,1,2)$ & -1.9464 & & & -1.6996 \\
\hline ARIMA $(2,1,2)$ & & & -1.8235 & \\
\hline SARIMA $(1,1,1)$ & & & & -1.5348 \\
\hline SARIMA $(2,1,2)$ & -1.7873 & & -1.4955 & \\
\hline SARIMA $(2,2,2)$ & & -1.437 & -1.4782 & -1.3524 \\
\hline
\end{tabular}

In Table 3, there are several ARIMA and SARIMA model that did not produce any results. This condition happens due to the characteristics within the exchange rate is not applicable in formulating the suitable models or the exchange rates are still in the state of non-stationary even though the differencing method is applied. The suitable model for each currency is chosen based on the smallest value from the AIC test. The most appropriate model to be applied based on the characteristic of the exchange rates are:

- $\quad \mathrm{USD}=\mathrm{ARIMA}(1,1,2)$.

- $\quad \mathrm{AUD}=\operatorname{SARIMA}(0,0,0)(2,2,2)$

- $\quad \mathrm{EUR}=$ ARIMA $(2,1,2)$

- $\quad \mathrm{JPY}=$ ARIMA $(1,1,2)$ 
From the AIC test shown in Table 3, only AUD/IDR exchange rates indicate a seasonal pattern. Which means there is repeated movement within the AUD/IDR which occurred in the period from 2008 to 2018.

Based on the result each currency holds their distinct regressive model, and we need to find the dependency level for each exchange rates relationship. Before we use the copula method to identify the where dependence occurs, we transform the daily returns of each currency into uniform distribution and present the transformation using a scatter plot. The scatter plot of the uniform distribution of each currency relationship is in Figure 3.
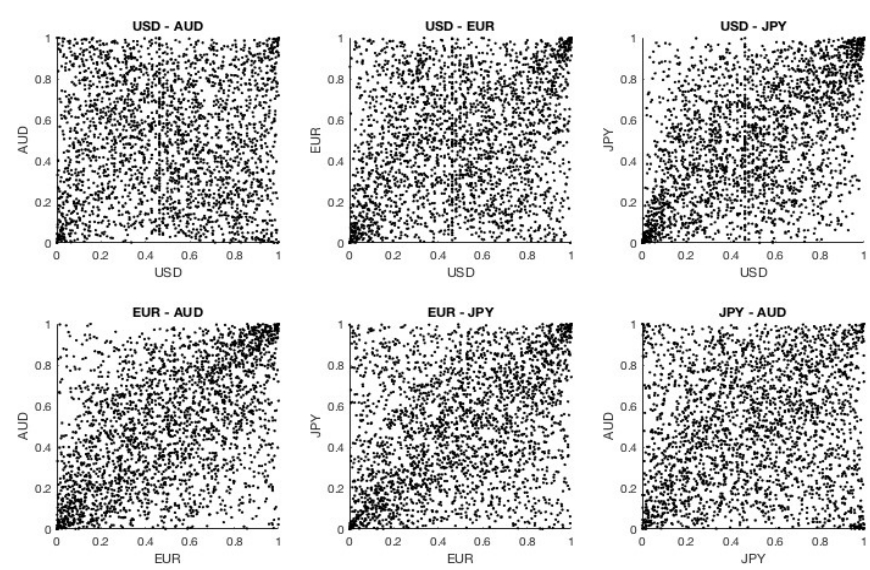

Figure 3. Uniform transformation.

From Figure 3, there are six relationships which indicate lower tail dependence. However, to entirely determined and captured its dependence level position of Kendall's tau test is implemented with the addition of log-likelihood to determine the best copula approaches that can capture the dependence nature of the exchange rates. The result of Kendall's tau test is in Table 4.

From Kendall's tau test, the Clayton copula has the highest log-likelihood value for all the exchange rates currencies. The result indicates that all the currencies relationship indicates lower tail dependence. 
Table 4. The Kendall's tau test.

\begin{tabular}{|c|c|c|c|c|}
\hline Currency Relations & Copula & Tau & Rho & Log Likelihood \\
\hline \multirow{3}{*}{ USD-AUD } & Clayton & \multirow{3}{*}{0.0164} & 0.1217 & 1544.20 \\
\hline & Frank & & 0.202 & 103.2592 \\
\hline & Gumbel & & 1.0682 & 1032.30 \\
\hline \multirow{3}{*}{ USD-EUR } & Clayton & \multirow{3}{*}{0.1788} & 0.4662 & 680.1987 \\
\hline & Frank & & 1.8252 & -101.3462 \\
\hline & Gumbel & & 1.2649 & 320.7656 \\
\hline \multirow{3}{*}{ USD-JPY } & Clayton & \multirow{3}{*}{0.3609} & 0.9371 & -120.2665 \\
\hline & Frank & & 3.8648 & -322.2151 \\
\hline & Gumbel & & 1.609 & -436.6636 \\
\hline \multirow{3}{*}{ EUR-AUD } & Clayton & \multirow{3}{*}{0.3567} & 0.8176 & 57.6862 \\
\hline & Frank & & 3.7805 & -312.7508 \\
\hline & Gumbel & & 1.5473 & -299.2785 \\
\hline \multirow{3}{*}{ EUR-JPY } & Clayton & \multirow{3}{*}{0.259} & 0.595 & 410.0987 \\
\hline & Frank & & 2.6647 & -194.1795 \\
\hline & Gumbel & & 1.3674 & 59.6916 \\
\hline \multirow{3}{*}{ JPY-AUD } & Clayton & \multirow{3}{*}{0.1156} & 0.2113 & 1178.10 \\
\hline & Frank & & 1.1186 & -14.3367 \\
\hline & Gumbel & & 1.1269 & 730.2408 \\
\hline
\end{tabular}

The most appropriate copula to be implemented based on the characteristic of the exchange rates relationship is Clayton copula. Based on the result in Table 4, we simplify the uniform distribution to capture the nature of the exchange rates dependencies using the parameters of the Clayton copula for each exchange rates relationship. The uniform distribution transformation of each exchange rate relationship using the Clayton copula is in Figure 4.
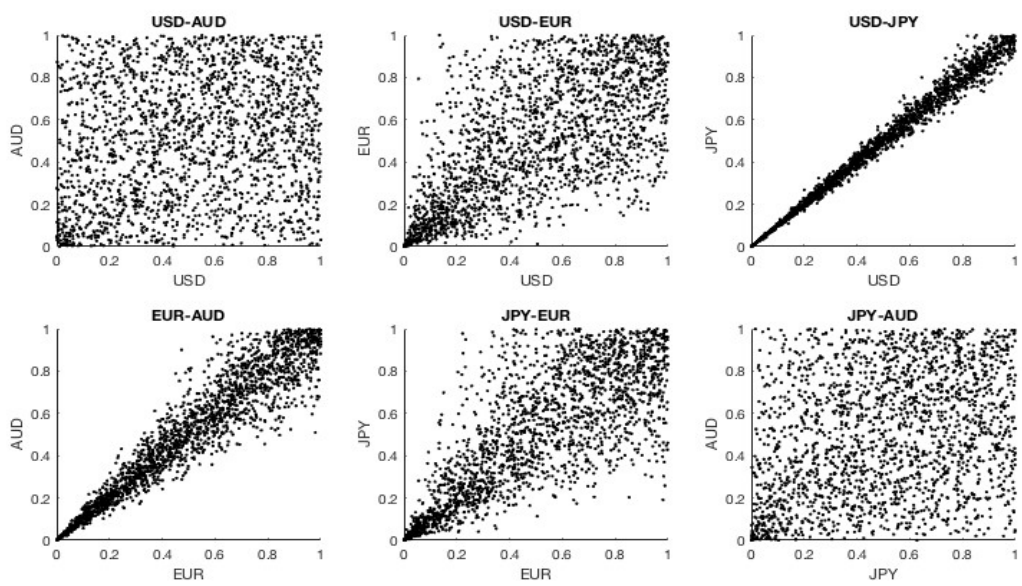

Figure 4. Clayton copula transformation.

Based on the Clayton copula transformation in Figure 4, there is heavy dependence in the lower tail. Which means, the exchange rates dependency is more related when positioned in small values. For example, in times of recession such as the financial crisis in 2008, the exchange rates relationship 
between USD, AUD, JPY and EUR against IDR are tended to be appreciated. Following the concept of Fréchet-Hoeffding bound in Clayton copula, it indicates that all the currencies relationship used in this research has a positive dependence or comonotonicity. In simple terms, if one of the exchange rates increasing, then the other currencies tend to be increasing as well.

The forecasted value of each currency is in Figure 5. The future value of the exchange rates between USD, JPY and EUR tend to move in a stable form, as shown in Figure 5. However, the future value of AUD tends to be weaker. In other words, IDR is tending to become stronger in the future. Regarding the implementation VaR estimation, the value of the future value of each currency combines with the characteristic of the Clayton copula to estimate the maximum potential losses of each exchange rate relationship within the $90 \%, 95 \%$ and $99 \%$ confidence interval. The usage of the Clayton copula and the forecasted value of the exchange rates on the estimating the maximum losses of the exchange rates relationship is conducted to maintain the relationship and the dependency characteristic while estimating the maximum losses.
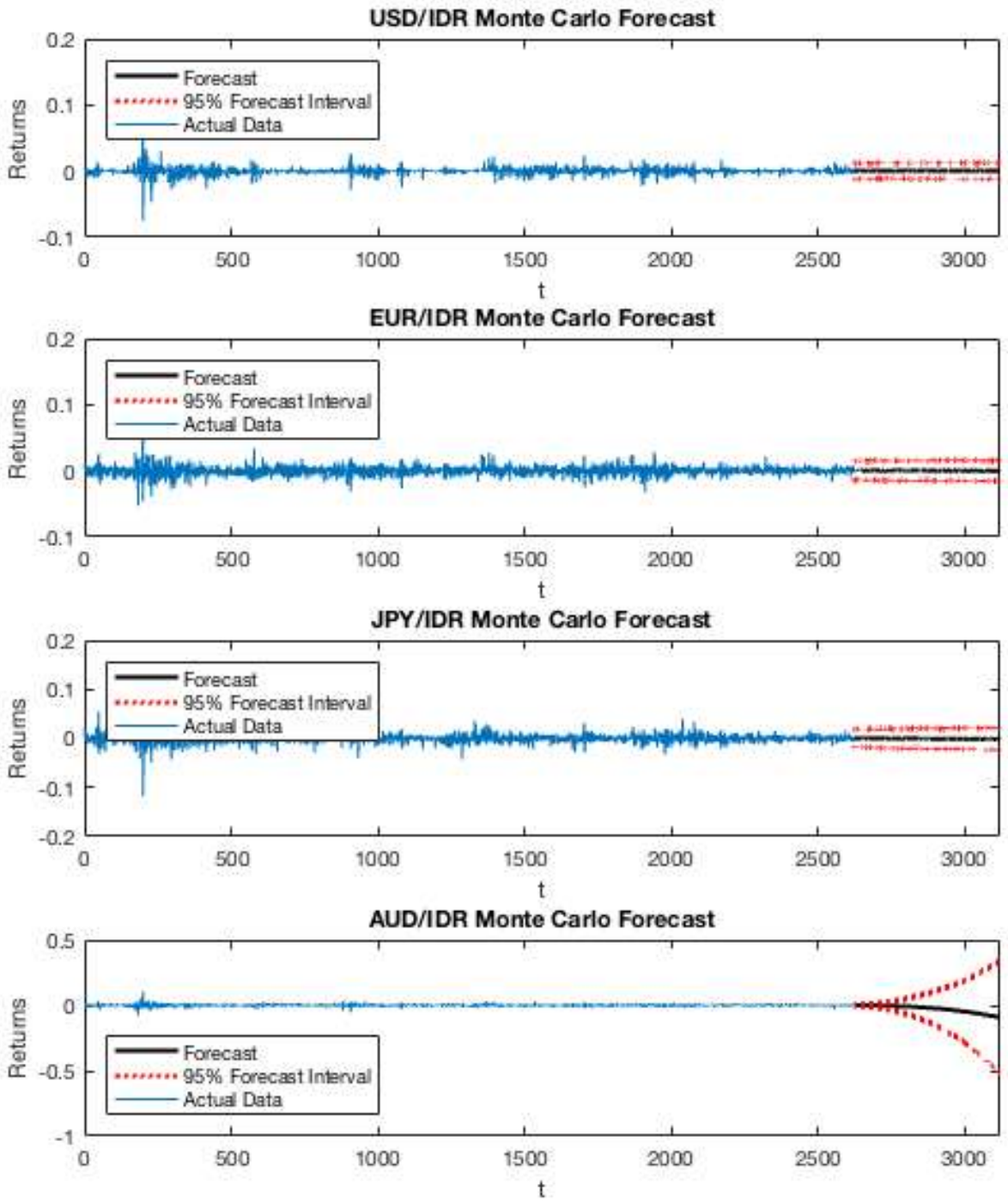

Figure 5. USD, AUD, EUR, JPY Daily Returns Forecast. 
Table 5Based on Table 5, The highest simulated gain belongs to JPY/IDR, and EUR/IDR with the maximum simulated gain stands at $72.362 \%$, and the exchange rate relationship with the least gain belongs to USD/IDR, and EUR/IDR with simulated gain stands at $18.419 \%$. Regarding the highest simulated loss on the exchange rate relationship, table 5 shows that the JPY/IDR and EUR/IDR relationship has the highest VaR estimation on $90 \%, 95 \%$ and $99 \%$ confidence level and with the highest potential losses.

Table 5. Simulated VaR, losses and gains.

\begin{tabular}{lcccccc}
\hline \multirow{2}{*}{ Estimation } & \multicolumn{5}{c}{ Currency Relationship } \\
\cline { 2 - 7 } & USD - AUD & USD - EUR & USD - JPY & AUD - EUR & AUD - JPY & JPY - EUR \\
\hline $\begin{array}{l}\text { Maximum } \\
\text { simulated } \\
\text { loss }\end{array}$ & $-42.443 \%$ & $-18.496 \%$ & $-19.284 \%$ & $-51.105 \%$ & $-56.176 \%$ & $-72.663 \%$ \\
\hline $\begin{array}{l}\text { Maximum } \\
\text { simulated } \\
\text { gain }\end{array}$ & $42.267 \%$ & $18.419 \%$ & $19.204 \%$ & $50.893 \%$ & $55.943 \%$ & $72.362 \%$ \\
\hline & & & & & & \\
\hline $\begin{array}{l}\text { Simulated } \\
90 \% \text { VaR }\end{array}$ & $-18.643 \%$ & $-8.124 \%$ & $-8.470 \%$ & $-22.447 \%$ & $-24.675 \%$ & $-31.917 \%$ \\
\hline $\begin{array}{l}\text { Simulated } \\
95 \% \text { VaR }\end{array}$ & $-23.545 \%$ & $-10.260 \%$ & $-10.698 \%$ & $-28.350 \%$ & $-31.163 \%$ & $-40.309 \%$ \\
\hline $\begin{array}{l}\text { Simulated } \\
99 \% \text { VaR }\end{array}$ & $-32.349 \%$ & $-14.097 \%$ & $-14.698 \%$ & $-38.951 \%$ & $-42.817 \%$ & $-55.383 \%$ \\
\hline
\end{tabular}

\section{Conclusion}

In this paper, we have conducted the application of copula methods and Monte Carlo simulations on USD, AUD, EUR and JPY to IDR to find VaR estimates for each exchange rate relationship and future value for each currency. From the model selection test, AUD / IDR has an indication of seasonal patterns in the exchange rate and the SARIMA model is only applied to AUD / IDR, while the rest uses the ARIMA model for estimation mechanisms using Monte Carlo simulations and VaR estimation is in $90 \%, 95 \%, 99 \%$ confidence intervals.

Following Diks et al. (2010), the conditions and the characteristic of the exchange rates are heavily determined the simulated result and the parameters to imitate the potential movement of the exchange rates. In our case, there are still unknown factors within the time series data that are showing a seasonal pattern (which are AUD/IDR). This seasonal pattern heavily influences the simulated forecasting result. The result implies that there is a need to differentiate the technique to tackle this seasonality pattern within time series data.

Based on Kendall's tau test, Clayton copula is the most suitable copula to be applied based on the characteristic of exchange rates nature for all relationship between USD, AUD, EUR and JPY against IDR. The result indicates a high dependence level in the lower tail of the distribution, attaining the Fréchet-Hoeffding upper bound.

The highest VaR estimation in $90 \%, 95 \%$ and $99 \%$ confidence interval and with the highest maximum simulated loss belong to JPY/IDR and EUR/IDR relationship.

In this paper, we have conducted the simulation based on the specification and the definition of the Archimedean copula and time series forecasting model for the seasonal and non-seasonal pattern. However, the forecasting result and the VaR estimation may act differently due to the seasonality pattern. For this problem, we leave it for future research to investigate why does the seasonality pattern might occur and how does the seasonality pattern produce a very different result compare to the non-seasonal time series data. 


\section{References}

Adamko, P., Spuchl'áková, E. \& Valášková, K., 2015. The History and Ideas Behind VaR. Procedia Economics and Finance, Volume 24, pp. 18-24.

Alexandrov, V., Martel, C. G. \& Staßburg, J., 2011. Monte Carlo scalable algorithms for Computational Finance. Procedia Computer Science, Volume 4, pp. 1708-1715.

Appiah, S. T. \& Adetunde, I. A., 2011. Forecasting exchange rate between the Ghana cedi and the US dollar using time series analysis. Current research journal of economic theory, 3(2), pp. 76-83.

Aven, T., 2016. Risk assessment and risk management: Review of recent advances on their foundation. European Journal of Operational Research, 253(1), pp. 1-13.

Bank Indonesia, 2018. Kurs Transaksi Bank Indonesia. [Online] Available at: https://www.bi.go.id/id/moneter/informasi-kurs/transaksi-bi/Default.aspx

Box, G. E. P., Jenkins, G. M., Reinsel, G. C. \& Ljung, G. M., 2016. Time Series Analysis: Forecasting $\&$ Control. 5th ed. New Jersey: John Wiley \& Sons.

Cakir, H. M. \& Uyar, U., 2013. Portfolio Risk Management with Value at Risk: A Monte-Carlo Simulation on ISE-100. International Research Journal of Finance and Economics, Issue 109.

Chen, N. \& Hong, L. J., 2007. Monte Carlo simulation in financial engineering. Proceeding of the 2007 Winters Simulation Conference, pp. 919-931.

Cho, S. \& Shin, D. W., 2016. An integrated heteroscedastic autoregressive model for forecasting realized volatilities. Journal of the Korean Statistical Society, 45(3), pp. 371-380.

Coval, J. D., Jurek, J. W. \& Stafford, E., 2009. Economic catastrophe bonds. American Economic Review, 99(3), pp. 628-666.

Délèze, F. \& Korkeamäki, T., 2018. Interest rate risk management with debt issues: Evidence from Europe. Journal of Financial Stability, Volume 36, pp. 1-11.

Diks, C., Panchenko, V. \& van Dijk, D., 2010. Out-of-sample comparison of copula specifications in multivariate density forecasts. Journal of Economic Dynamics and Control, 34(9), pp. 15961609.

Dionne, G., 2013. Risk management: History, definition, and critique. Risk Management and Insurance Review, 16(2), pp. 147-166.

Embrechts, P., McNeil, A. \& Straumann, D., 1999. Correlation: pitfalls and alternatives. Risk Magazine.

Fink, H., Fuest, A. \& Port, H., 2018. The Impact of Sovereign Yield Curve Differentials on Valueat-Risk Forecasts for Foreign Exchange Rates. Risks, 6(3), p. 84.

Hallikas, J. et al., 2004. Risk management processes in supplier networks. International Journal of Production Economics, 90(1), pp. 47-58.

Hardy, D. C. \& Pazarbaşioğlu, C., 1998. Lending Indicators of Banking Crises: Was Asia Different?. IMF Working Paper, Volume WP/98/91.

Ito, T., Koibuchi, S., Sato, K. \& Shimizu, J., 2015. Exchange rate exposure and risk management: The case of Japanese exporting firms, New York: Center on Japanese Economy and Business, Graduate School of Business, Columbia University.

Jorion, P., 2009. Financial Risk Manager Handbook. 5th ed. New Jersey: John Wiley \& Sons.

Kaminsky, G. L. \& Reinhart, C. M., 1999. The twin crises: the causes of banking and balance-ofpayments problems. American Economic Review, 89(3), pp. 473-500.

Kawakami, K., 2013. Conditional forecast selection from many forecasts: An application to the Yen/Dollar exchange rate. Journal of the Japanese and International Economies, Volume 28, pp. 1-18.

Khalaf, L. \& Saunders, C. J., 2017. Monte Carlo forecast evaluation with persistent data. International Journal of Forecasting, Volume 33, pp. 1-10. 
Krugman, P., Obstfeld, M. \& Melitz, M. J., 2018. International Economics: Theory and Policy. 11th ed. Harlow: Pearson Education.

Lidiema, C., 2017. Modelling and Forecasting Inflation Rate in Kenya Using SARIMA and HoltWinters Triple Exponential Smoothing. American Journal of Theoretical and Applied Statistics, 6(3), pp. 161-169.

Mahfoud, M. \& Massmann, M., 2012. Bivariate Archimedean copulas: an application to two stock market indices. Vrije Universiteit Amsterdam BMI.

Makatjane, K. D., Molefe, E. K. \& van Wyk, R. B., 2018. The Analysis of the 2008 US Financial Crisis: An Intervention Approach. Journal of Economics and Behavioral Studies, 10(1), pp. 59-68.

Michalski, G., 2009. Inventory management optimization as part of operational risk management. Economic Computation and Economic Cybernetics Studies and Research, pp. 213-222.

Neftci, S. N., 2000. Value at risk calculations, extreme events, and tail estimation. Journal of Derivatives, pp. 1-15.

Nguyen, T. \& Molinari, R. D., 2011. Risk aggregation by using copulas in internal models. Journal of Mathematical Finance, Volume 1, pp. 50-57.

Ogawa, M. A., Costa, N. J. d. \& Moralles, H. F., 2018. Value-at-Risk (VaR) Brazilian Real and currencies of emerging and developing markets. Gestão \& Produção, 25(3), pp. 485-499.

Patton, A. J., 2006. Modelling asymmetric exchange rate dependence. International Economic Review, 47(2), pp. 527-556.

Platon, V. \& Constantinescu, A., 2014. Monte Carlo method in risk management analysis for investment projects. Procedia Economics and Finance, pp. 393-400.

Quang, P. B., Klein, T., Nguyen, N. H. \& Walther, T., 2018. Value-at-Risk for South-East Asian Stock Markets: Stochastic Volatility vs. GARCH. Journal of Risk and Financial Management, 11(2), pp. 1-20.

Righi, M. B. \& Ceretta, P. S., 2011. Estimating Value at Risk and Optimal Hedge Ratio in Latin Markets: A Copula-Based GARCH Approach. Economics Bulletin, 31(2), pp. 1717-1730.

Simatupang, B. M., 2007. Bank Recapitalization and Bank Performance in Real Sector Lending: Analysis of Indonesia's Economic Recovery from the Crises of 1997-1998. Maastricht: Maastricht School of Management.

Staum, J., 2002. Simulation in financial engineering. Proceeding of the 2002 Winter Simulation Conference, pp. 1481-1492. 